Article

\title{
Hydrophobic and Anti-Icing Behavior of UV-Laser-Treated Polyester Resin-Based Gelcoats
}

\author{
Rafał Kozera $^{1, *}$, Bartłomiej Przybyszewski ${ }^{1}{ }^{\circledR}$, Zuzanna D. Krawczyk $^{1}{ }^{\circledR}$, Anna Boczkowska ${ }^{1}(\mathbb{D}$, \\ Bogna Sztorch ${ }^{2}$, Robert E. Przekop ${ }^{2}$, Robert Barbucha ${ }^{3}$, Mateusz Tański ${ }^{3}$, \\ Xabier Garcia-Casas ${ }^{4}{ }^{-1}$ and Ana Borras 4 \\ 1 Faculty of Materials Science and Engineering, Warsaw University of Technology, ul. Woloska 141, \\ 02-507 Warszawa, Poland; bartlomiej.przybyszewski.dokt@pw.edu.pl (B.P.); \\ zuzanna.krawczyk2.stud@pw.edu.pl (Z.D.K.); anna.boczkowska@pw.edu.pl (A.B.) \\ 2 Centre for Advanced Technologies, Adam Mickiewicz University in Poznań, ul. Uniwersytetu Poznańskiego 10, \\ 61-614 Poznan, Poland; Bogna.Sztorch@amu.edu.pl (B.S.); robert.przekop@amu.edu.pl (R.E.P.) \\ 3 Institute of Fluid-Flow Machinery, Polish Academy of Sciences, Gdańsk, ul. Fiszera 14, \\ 80-231 Gdansk, Poland; brobert@imp.gda.pl (R.B.); tanski@imp.gda.pl (M.T.) \\ 4 Nanotechnology on Surfaces and Plasma, Institute of Materials Science of Seville, Spanish National Research \\ Council-University of Seville c/Américo Vespucio, 4941092 Isla de la Cartuja, Spain; \\ xabier.garcia@icmse.csic.es (X.G.-C.); anaisabel.borras@icmse.csic.es (A.B.) \\ * Correspondence: Rafal.Kozera@pw.edu.pl
}

Received: 9 November 2020; Accepted: 6 December 2020; Published: 12 December 2020

check for updates

\begin{abstract}
Ice accumulation on wind turbine blades due to the impact of supercooled water droplets can be reduced by the application of surfaces with anti-icing properties. Hydrophobic surfaces are considered as a promising solution because of their water repellent behavior. In recent years, short-pulsed laser technologies have been developed as an efficient technique to modify the surface properties of materials. However, the anti-icing properties of such surfaces have not yet been validated. In this work, a hybrid modification of polyester resin-based gelcoats was adopted. Laser patterning (LP) was used to produce periodic surface structures on modified unsaturated polyester resin (UPR) substrates. One of the innovations of this research is the utilization of novel purpose-made chemical modifiers for gelcoats. The implementation of linear polymethylhydrosiloxane (PMHS) as a building block is a key improvement in terms of durability and functionality of the coating, since there is an option of introducing not only groups bonding in the polyester into one molecule, but also groups that increase hydrophobicity. The other novelty is a successfully conducted experiment combining such chemical modification with laser texturization of the surface. The influence of the laser energy, pattern shape, and spatial periods on the topographical characteristics and hydrophobicity as well as the anti-icing properties of the produced surfaces were investigated. To characterize the surface topography of the produced structures, scanning electron microscopy (SEM) and profilometer were utilized. Measurements of the wettability parameters (static contact angle and contact angle hysteresis) on the treated surfaces allowed the identification of the influence of wetting behavior and laser parameters on the investigated materials. Anti-icing properties were characterized by ice adhesion (IA) and freezing delay time (FDT) tests. It was found that hybrid modification of unsaturated polyester resin by chemical modifiers and laser treatment increased the hydrophobic and anti-icing properties of polyester gelcoats.
\end{abstract}

Keywords: icephobicity; hydrophobicity; ice adhesion; unsaturated polyester resin; polyhedral oligomeric; silsesquioxane; freezing delay time; laser texturization 


\section{Introduction}

In the modern world, energy sources are one of the most widely discussed topics, the debate arising from an increasing environmental awareness in society and a decreasing number of finite resources such as coal or natural gas. Studies have shown that around $15 \%$ of the total electricity generated in the European Union in 2019 came from wind power plants and there are goals set to further improve the statistics [1]. Moreover, wind energy accounted for $7.5 \%$ of utility-scale electricity generation in the USA in the same year [2]. Hence, it is essential to warrant the durability, cost-efficiency, and safeness of the wind turbines and take into consideration the main setbacks in the process of their design [3]. For instance, the environment in which wind turbines operate is not the most indulgent one. The blades are exposed to not only rain, but also snow and low temperatures that may lead to the formation of ice on the surface [4]. It is worth mentioning that wind power plants are widely applied in rather cold Scandinavian countries, with Sweden making up 10\% of the wind energy produced in the European Union [1].

The most serious problem linked to the wind turbine's exposure to heavy rain is water droplet erosion. The mechanism of liquid erosion is based on the drop surface of the blade moving at high velocity and may lead to extensive cracking or material loss $[5,6]$. Hence, there is a demand for superhydrophobic polymer materials and there are various methods of producing them, including plasma etching, spray coating, sol-gel process, and lithography. Another review [7] has discussed different approaches to the fabrication of polymer nanocoatings. Paper [8] has presented Polytetrafluoroethylene/Heat-Shrinkable Polyvinyl Chloride (PTFE/HSPVC) composite film with contact angle of $150^{\circ}$ that may be utilized in wind turbines. In other research [9], a method that is applicable for different polymers, such as Poly(methyl methacrylate), Polystyrene, Polycarbonate and thermoplastic polyurethane has been proposed. A review [10] has also underlined the crucial impact of surface roughness on its wettability.

Accumulation of ice on the blades may also have severe effects on its exploitation. Depending on the ice formed, the outcomes may vary, but generally include reduction in airfoil efficiency, aerodynamic and mass imbalance, increased fatigue loads, and even stoppage of turbine blade operation. Furthermore, it is a complex issue to forecast the type of ice accretion, its distribution, and hence the precise effect on the physical properties of the material [11,12]. Traditionally, active de-icing techniques-thermal, chemical, or mechanical-are implemented, however, they require appropriate maintenance and well-timed action. Moreover, chemical techniques' negative environmental impact should be taken into consideration [13,14].

Therefore, the ideal solution would be to prevent the formation of ice, which may be achieved using passive anti-icing techniques, i.e., the utilization of icephobic coatings, such as polydimethylsiloxane (PDMS)-based ones, which achieve low values of ice adhesion strength. Those coatings also minimize the risk of the appearance of liquid erosion, as lower ice adhesions characterize more hydrophobic materials [15]. According to researchers, nano- or microstructured surfaces may increase the hydrophobicity of the material and its anti-icing characteristics. This idea was copied from nature, as there are some naturally occurring structured superhydrophobic materials, with the lotus leaf as a key example [16]. There are multiple research studies on the topic of designing icephobic structures and the relation between hydrophobicity and anti-icing properties [17-19]. In the article [20], different artificially created patterns were tested, including posts, bricks, blades and honeycombs and the conclusion was drawn that the design of nanostructured materials should in fact lead to reducing or eliminating ice accumulation. Scientific review [21] juxtaposed "top-down" and "bottom-up" methods and their mixture on various materials, presenting them as successful, although to varying degrees.

Nonetheless, it should be noted that there are many issues with the traditional techniques regarding the fabrication of such coatings, for instance, its cost and complexity [18]. Hence, it is suggested that laser patterning could be implemented on wind turbine blades' coatings to achieve a periodically structured surface. Among the advantages of the method, the control of properties based on chosen parameters and economic efficiency should be appreciated [22]. Utilization of laser radiation should minimize the complexity of the process; however, the parameters of operation should 
be picked carefully to avoid material damage $[23,24]$. Moreover, appropriately chosen hatch spacing and laser power in order to obtain better hydrophobic and anti-icing properties [25,26]. Even though it is the simplest one, line geometry was proven to bring positive results. Another popular shape is the square (two perpendicular lines) [27-29]. Modification of the second solution was introduced in this paper, adding a third line rotated by $45^{\circ}$ to form triangles.

The idea of surface modification using infrared laser radiation has already been applied successfully to aluminum and aluminum alloy substrates [22,30]. Sprayed dual layer coating (tertiary butyl acetate based as the bottom layerr and PTFE based as the top one) in juxtaposition with sprayed coating combined with laser patterning on titanium alloy displayed the superiority of the latter treatment [31]. Another research study has managed to achieve superhydrophobicity of steel with laser [32,33]. For polymers, it has been proposed to adopt ultraviolet laser radiation, which was tested with satisfactory outcomes on polystyrene and polyimide substrates $[34,35]$. There have also been experiments on direct laser interference patterning comparing UV and IR radiation effects on polycarbonate substrates with the clear conclusion that laser type and parameters should be chosen carefully for particular materials [36]. When laser patterning was tested on silicone elastomers, the samples exhibited superhydrophobicity and remained water repellent even after stretching [28]. However, there have been studies that stress that materials may lose their enhanced properties when put in their operating environment [37].

There are many strategies to obtain surfaces with hydrophobic or icephobic properties. In scientific literature, the interest in this type of material construction has been observed over a relatively short period, since the first decade of the 21st century. From the point of view of the complexity of the structure (at the micro- or nanometric level), icephobic coatings are characterized by a much higher level of complications and complexity compared to hydrophobic surfaces [17]. This observation is important in the context of the division of modifiers used in icephobization technologies. The phenomena in question require both a properly structured $[38,39]$ surface as well as appropriate chemical treatment at the level of nanometer-thick layers leading to a reduction in surface energy [40].

In the field of chemical modification of coatings, one of the most effective modifiers are organosilicon compounds, i.e., silanes, siloxanes, and silsesquioxanes, mainly due to their chemical structure and properties. These properties are directed by various functional groups occurring in organosilicon bonds, characterized on the one hand by the presence of various organic groups and, on the other hand, by silanol groups capable of forming permanent covalent bonds with the surface

One of the most commonly used organosilicon modifiers is polymethylhydrosiloxane (PMHS), mainly due to its high chemical stability under atmospheric conditions (also at high humidity), nontoxicity and low price [41,42]. In addition, polyhydrogen, siloxanes, and hydrodisiloxanes, due to the presence of the reactive Si-H group, can be modified with selected functional groups in the hydrosilylation reaction, which allows for a wide control of hydrophobic, rheological or dispersion properties. This allows the properties of siloxane to be matched to the polymer matrix with which it is to be compounded to obtain a material with high homogeneity and desired properties [43]. The majority of data available in scientific literature are based on the application of functionalized linear polyhydrosiloxanes and polysiloxanes with only one functional group as agents that increase hydrophobic properties [44]. Moreover, unifunctionalized polysiloxanes have been introduced to epoxy resin-based composites, resulting in a material with improved performance [45]. Double-functionalized polysiloxanes are mostly utilized to modify fibers in the textile industry [46]. There are hardly any papers discussing double-functionalized polysiloxanes as modifiers that increase icephobicity. Hence, it is reasonable to assume that there are realistic chances of achieving composite coatings with desirable, durable, and stable properties, which are widely applied on the surface of wind turbine blades. The goal and novelty of this article is to carry out research on the hydrophobic and anti-icing properties of unsaturated polyester resin-based gelcoats with the addition of authors' chemical modifiers from the group of polyhedral oligomeric silsesquioxane after surface modification by means of laser patterning with ultraviolet radiation (wavelength $355 \mathrm{~nm}$ ). To accurately characterize the materials, scanning 
electron microscopy was implemented, the surface's profile was obtained, and the following parameters: wettability, surface roughness, ice adhesion, and freezing time delay were measured. The results obtained show that hydrophobicity may be improved as a result of laser processing, whereas chemical modifiers provide better anti-icing properties.

\section{Materials and Methods}

The material used in the present study was gelcoat based on unsaturated polyester resin (UPR) BÜFA ${ }^{\circledR \circledR}$-Arctic-Gelcoat-ISO-S (BÜFA, Oldenburg, Germany), which is a preaccelerated gelcoat with a spraying consistency. The base resin is a pure isophthalic acid resin dissolved in styrene and hydroxyethylmethacrylate (HEMA). BÜFA ${ }^{\circledR}$-Arctic-Gelcoat-ISO-S is suitable for molded parts that are subject to heavy weathering or normal hydrolysis loads (e.g., in boat construction).

The main goal of this study was to use the original organosilicon modifiers in the form of double-functionalized PMHS (Figure 1). These modifiers have hydrophobic alkyl groups and alkoxy groups that act as a cross-linking function on the resin, leading to the modifier's immobilization in the gelcoat structure. The substances used in the modifier synthesis were: silicon compounds (trimethylsiloxy-terminated polymethylhydrosiloxanes (PMHS) and olefins (vinyltrimethoxysilane, hexene, octane) purchased from Linegal Chemicals Warsaw, Poland, solvent (toluene) from Avantor Performance Materials Poland S.A. Gliwice, Poland and chloroform-d, toluene- d8, Karstedt catalyst from Sigma Aldrich Poland, Poznan, Poland. In the process, toluene was dried and purified with MB SPS 800 Solvent Drying System and stored under argon atmosphere in Rotaflo Schlenk flasks.

Additives were fabricated according to the following recipe. Mixture of vinyltrimethoxysilane $(0.168 \mathrm{~mol})$ and hexene $(0.336 \mathrm{~mol})$ in a molar ratio of $1: 2$ (SILOX1), vinyltrimethoxysilane $(0.1008 \mathrm{~mol})$ and octene $(0.4032 \mathrm{~mol})$ in a molar ratio of 1:4 (SILOX2) and vinyltrimethoxysilane $(0.168 \mathrm{~mol})$ and octene $(0.336 \mathrm{~mol})$ in a molar ratio of 1:2 (SILOX3) were added to the solution of trimethylsiloxy-terminated polymethylhydrosiloxanes $(30 \mathrm{~g}, 0.504 \mathrm{~mol})$ in toluene. The mixture was constantly stirred and heated to $70^{\circ} \mathrm{C}$. Then, we added to the system an amount that varied from $8 \times 10^{-5} \mathrm{eq}$. of Karstedt catalyst. The reaction mixture was heated in reflux and stirred until the full conversion of $\mathrm{Si}-\mathrm{H}$ was detected using FT-IR.

Utilizing Bruker Ascend 400 and Ultra Shield 300 spectrometers (both from Bruker Poland ), $1 \mathrm{H}$, 13C, and 29Si nuclear magnetic resonance (NMR) spectra were then recorded at $25^{\circ} \mathrm{C}$ using $\mathrm{CDCl} 3$ as a solvent. Chemical shifts were reported in $\mathrm{pm}$ for $1 \mathrm{H}$ and $13 \mathrm{C}$ with reference to the residual solvent ( $\mathrm{CHCl} 3)$ peaks.

Fourier transform-infrared (FT-IR) spectra were obtained as well. The machine used was a Nicolet iS 50 Fourier transform spectrophotometer (Thermo Fisher Scientific, Walsham, MA, USA) equipped with a diamond ATR (attenuated total reflectance) unit with a resolution of $0.09 \mathrm{~cm}^{-1}$.

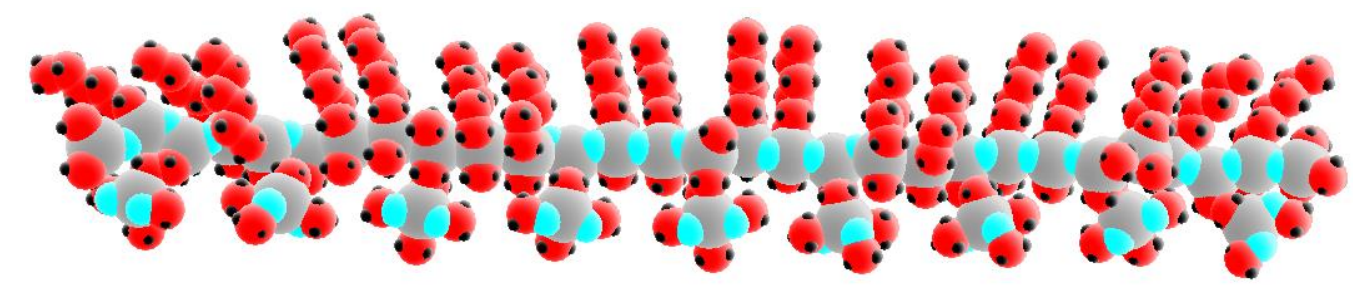

Figure 1. Structure of the linear modifier (double-functionalized polymethylhydrosiloxane (PMHS)).

The samples for mechanical tests were prepared by adding $5 \mathrm{wt} . \%$ of chemical modifiers to the resin. Then, the mixture was deaerated in a vacuum chamber and 1.5\% of Butanox M-50 initiator was added. The frames of thickness of $1 \mathrm{~mm}$ were applied on glass plates and the gelcoat was molded in them. Carbon fibers were put in the handle part of the sample (the area installed in the testing machine) to increase its strength. Upon completion of cross-linking, the samples were glued by the aid of chemically unmodified resin and as a result, specimens with a thickness of $3 \mathrm{~mm}$ were formed. 
The Nd:YAG ultraviolet laser used in the processing of the samples was Matrix 355 from Coherent with a laser beam wavelength of $355 \mathrm{~nm}$ and an average power of $5 \mathrm{~W}$. The pulse repetition frequency was set to $50 \mathrm{kHz}$ and the duration of the laser pulse was $35 \mathrm{~ns}$. The galvanometer InteliSCAN 14 from Scanlab was used to enable laser marking. The changeable parameters in the experiment were the laser power and linear laser beam speed (50-150 mm/s). In Figure 2, two different produced patterns are shown. The designs were created using Corel Draw and Inkscape software.

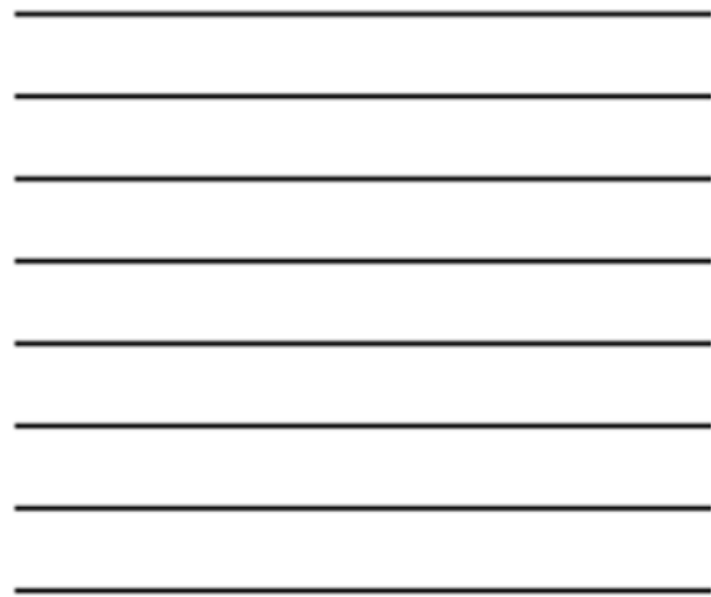

(a)

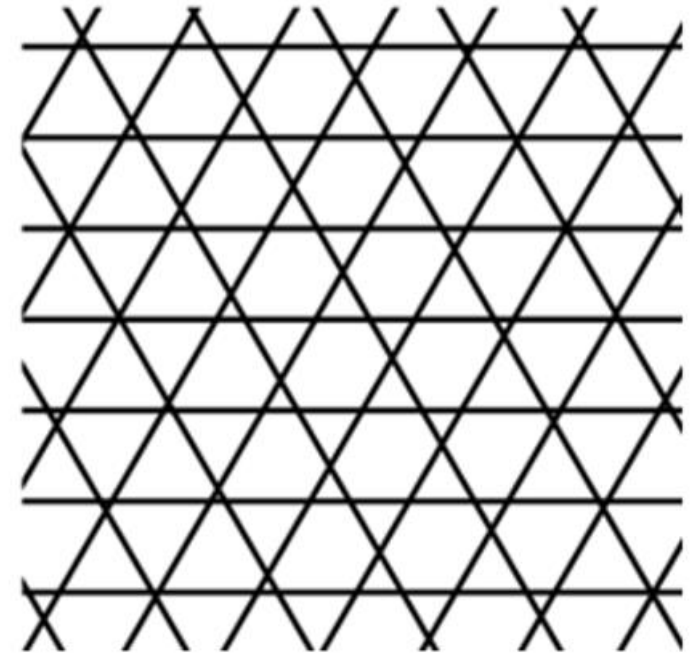

(b)

Figure 2. Patterns produced in the research: (a) line (b) triangles.

In Table 1, the laser processing parameters of the analysed specimens are shown.

Table 1. Laser processing parameters.

\begin{tabular}{ccccc}
\hline $\begin{array}{c}\text { Sample Processing } \\
\text { Type No. }\end{array}$ & Lens $(\mathbf{m m})$ & Pattern & Laser Power $(\mathbf{W})$ & Spacing Distance $(\boldsymbol{\mu m})$ \\
\hline 1 & 34 & Lines & 2 & 100 \\
2 & 34 & Lines & 3 & 100 \\
3 & 100 & Triangles & 3 & 180 \\
4 & 100 & Triangles & 2.5 & 120 \\
\hline
\end{tabular}

Prepared samples were investigated with the aid of scanning electron microscopy (SEM). The surfaces of the samples were observed using the TM-3000 Hitachi scanning electron microscope (Hitachi, Tokyo, Japan). Profilometer HOMMEL TESTER T8000 (Jenoptik, Jena, Germany) with probe TKU 300 and dedicated computer software (TURBO WAVE V7.62 for roughness testing and HommelMap Expert 5.0 for the creation of surface topographic maps) were implemented in the research as well. The probe's measuring range was $\pm 80 \mu \mathrm{m}$ and its measuring speed was $0.15 \mathrm{~mm} / \mathrm{s}$. To study the roughness of the specimens, values of arithmetic average height $\left(R_{a}\right)$ and ten-point height $\left(R_{z}\right)$ were obtained [47]. For the analysis of the surface's topography, 150 profiles for each sample were obtained, with a sampling area of $1.5 \times 1.5 \mathrm{~mm}$ and scan length of $0.01 \mathrm{~mm}$.

The key characteristic required when considering the hydrophobicity of a material is wettability. Data were collected using Goniometer OCA and SCA software from DataPhysics Instruments (DataPhysics, Filderstadt, Germany)). In one step of the experiment, the static contact angles $\theta$ 
were obtained. In the second part (needle-in-drop type measurements), dynamic contact angles were obtained. Contact angle hysteresis $\Delta \theta(C A H)$ was calculated using the equation:

$$
\Delta \theta=\theta_{A}-\theta_{R}
$$

where $\theta_{R}$ is the receding contact angle and $\theta_{A}$ is the advancing contact angle [48]. It is widely accepted within the scientific community that the condition for hydrophobicity is $\theta>90^{\circ}$ and for superhydrophobicity $\theta>150^{\circ}$ [49].

Designated specimens were manufactured for ice adhesion $(I A)$. They had dimensions $100 \times 25 \mathrm{~mm}$. After the process, laser patterning was performed on the prepared samples. The obtained specimens were secured in a metallic handle and distilled water was poured into the handle. Then, the samples were put in $-10{ }^{\circ} \mathrm{C}$ for $24 \mathrm{~h}$ in order for freezing to occur. Afterwards, the ice adhesion test in shear mode was conducted and the specimens were installed in the universal testing machine Zwick/Roell Z050. The value of ice adhesion strength $(\tau)$ was obtained from Equation (2):

$$
\tau=\frac{F}{A}
$$

where $F$ is the maximum force of the trial and $A$ is the contact area between ice and the sample [50].

Another experiment was aimed at determining the freezing delay time (FDT) with respect to the reference gelcoat sample (with no modifiers). Goniometer OCA15 from DataPhysics with a chamber provided with a thermoelectric cooler was used. There was a nitrogen atmosphere maintained in the chamber to preserve low humidity. At the beginning of the process, at the temperature of $10^{\circ} \mathrm{C}$, a water droplet was put on the surface of the sample and the contact angle was measured. Thereafter, the chamber was cooled to $-5{ }^{\circ} \mathrm{C}$ and the time necessary for the whole droplet to freeze was recorded. The process was repeated three times.

\section{Results}

\subsection{Characterization of Organosilicon Modifiers}

All organosilicon modifiers were prepared according to the synthesis procedure in the previous section. They were investigated by NMR and FT-IR spectroscopy to prove the completion of reactions (the disappearance of the characteristic signal was observed at 2141 and $889 \mathrm{~cm}^{-1}$, due to stretching and bending of the Si-H group, respectively). For all compounds, the hydrosilylation proceeded to completion of reactions $(\sim 99 \%)$. The structure and purity of the modifiers were confirmed by NMR analysis. It was observed that the hydrosilylation of olefins selectively proceeded to the $\beta$-isomer, except for trimethoxysilylethyl, where the formation of $\alpha$-isomers was also observed in a proportion of $\sim 30 \%$ in all cases (SILOX1 = 31\% (Figure 3), SILOX2 = 33\% (Figure 4), SILOX3 = 34\% (Figure 5)).
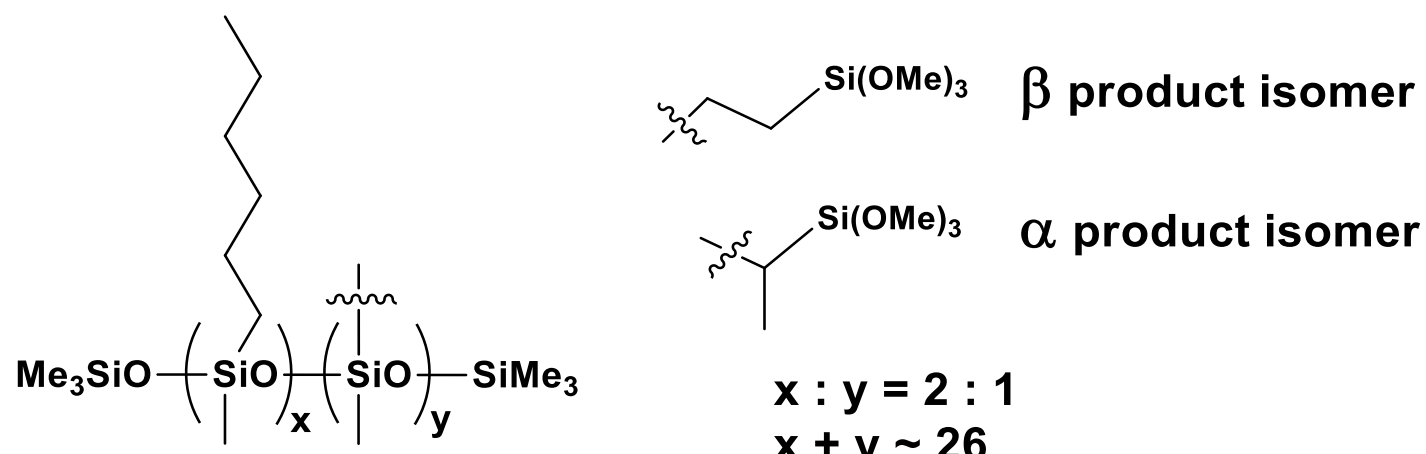

$$
\begin{aligned}
& x: y=2: 1 \\
& x+y \sim 26
\end{aligned}
$$

Figure 3. Synthesis of trimethylsilyl-terminated poly((hexylmethylsiloxane)-co-(methyl)(trimethoxysilyl)ethyl) siloxane)) (SILOX 1). 


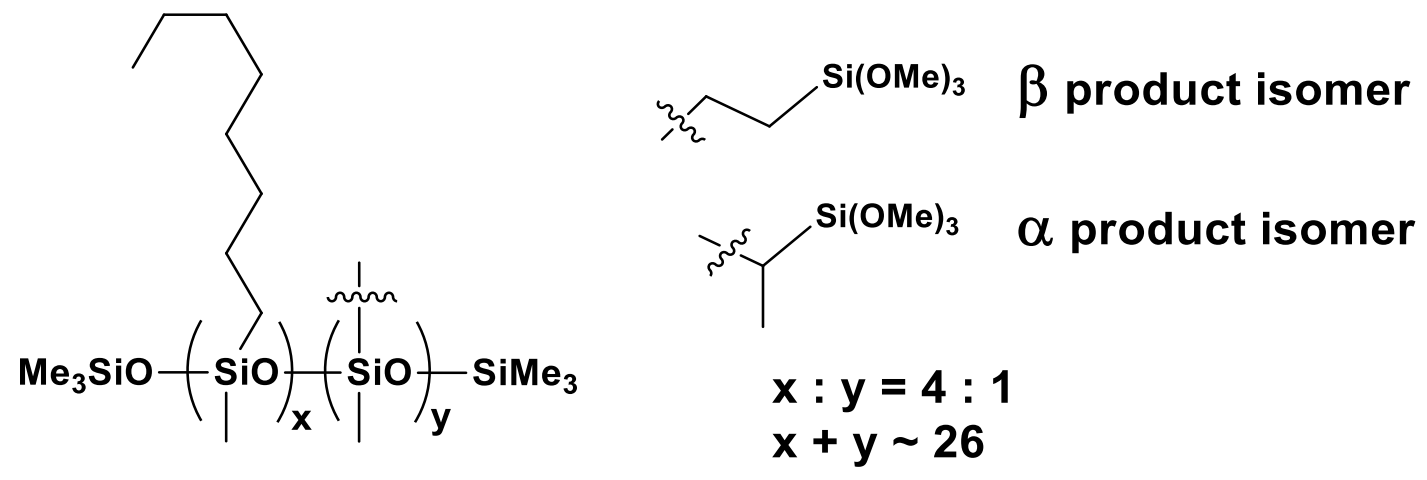

Figure 4. Trimethylsilyl-terminated poly((methyloctylsiloxane)-co-(methyl)(trimethoxysilyl)ethyl)siloxane)) (SILOX2).
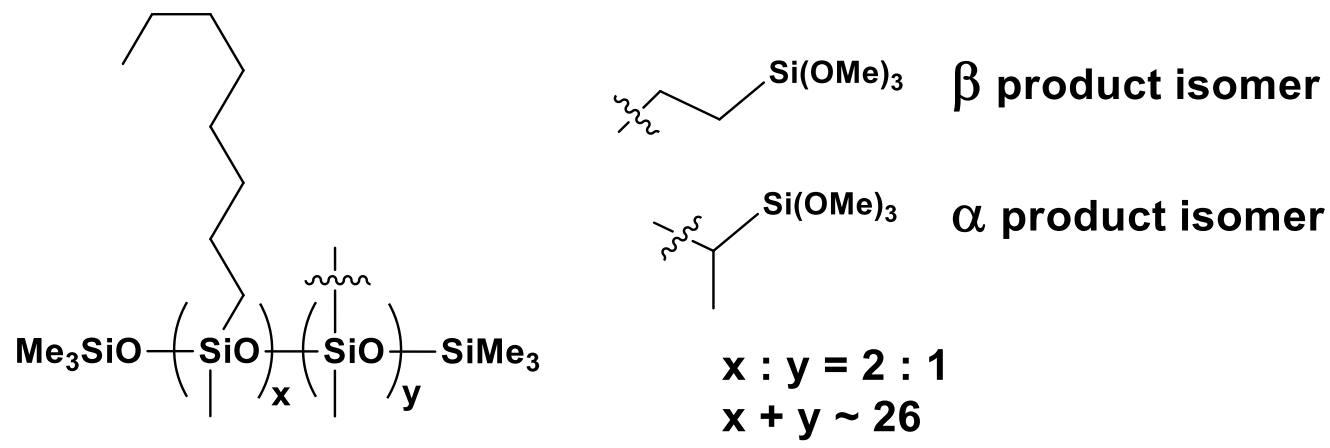

Figure 5. Trimethylsilyl-terminated poly((methyloctylsiloxane)-co-(methyl)((trimethoxysilyl)ethyl)siloxane)) (SILOX3).

The selectivity of the reaction, determined by NMR spectroscopy, showed that the product contained a mixture of trimethoxysilylethyl $\alpha$ and $\beta$ group in 31:69 ratio.

The purity and chemical structure of the compound were confirmed by NMR spectroscopy, the following signals were assigned:

${ }^{1} \mathrm{H}$ NMR $\left(400 \mathrm{MHz}, \mathrm{CDCl}_{3}\right): \delta(\mathrm{ppm})=3.55$ (s, OMe), 1.30-1.27 (m, hexyl - $\left.\mathrm{CH}_{2}-\right), 1.09(\mathrm{~d}$, $J=7.4 \mathrm{~Hz}$, trimethylsiloxy alpha product), $0.87\left(\mathrm{t}, J=6.3 \mathrm{~Hz}\right.$, hexyl $\left.-\mathrm{CH}_{3}\right), 0.61-0.50\left(\mathrm{~m}, \mathrm{SiCH}_{2} \mathrm{CH}_{2} \mathrm{Si}_{\text {, }}\right.$ $\left.\mathrm{SiCH}\left(\mathrm{CH}_{3}\right) \mathrm{Si}\right), 0.14,0.08,0.06,0.04$ (s, $\left.\mathrm{SiMe}_{2}, \mathrm{SiMe}_{3}\right)$;

${ }^{13} \mathrm{C}$ NMR $\left(101 \mathrm{MHz}, \mathrm{CDCl}_{3}\right): \delta(\mathrm{ppm})=50.67,50.61(\mathrm{OMe}), 33.28,31.81,23.19,23.06,22.80$, $17.85,14.24$ (hexyl chain), $8.45\left(\mathrm{Si}-\mathrm{CH}_{2} \mathrm{CH}_{2}-\mathrm{Si}\right), 7.60,5.11\left(\mathrm{SiCH}\left(\mathrm{CH}_{3}\right) \mathrm{Si}\right), 1.98,1.59,0.67,-0.21,-1.14$ $\left(\mathrm{Si}-\mathrm{CH}_{2} \mathrm{CH}_{2}-\mathrm{Si}, \mathrm{SiMe}_{2}, \mathrm{SiMe}_{3}\right)$;

${ }^{29} \mathrm{Si} \operatorname{NMR}\left(79,5 \mathrm{MHz}, \mathrm{CDCl}_{3}\right): \delta(\mathrm{ppm})=-21.24(-22.64)$ (siloxane chain), $-41.51(-41.65)$ $\left(\mathrm{Si}(\mathrm{OMe})_{3}\right)$.

The selectivity of the reaction, determined by NMR spectroscopy, shows that the product contains a mixture of trimethoxysilylethyl $\alpha$ and $\beta$ group in 33:67 ratio.

The purity and chemical structure of the compound were confirmed by NMR spectroscopy, the following signals were assigned:

${ }^{1} \mathrm{H}$ NMR $\left(400 \mathrm{MHz}, \mathrm{CDCl}_{3}\right): \delta(\mathrm{ppm})=3.56(\mathrm{~s}, \mathrm{OMe}), 1.30-1.26\left(\mathrm{~m}\right.$, octyl $\left.-\mathrm{CH}_{2}-\right), 1.09(\mathrm{~d}, J=7.4 \mathrm{~Hz}$, trimethylsiloxy alpha product), $0.88\left(\mathrm{t}, J=6.5 \mathrm{~Hz}\right.$, octyl $\left.-\mathrm{CH}_{3}\right), 0.61-0.50\left(\mathrm{~m}, \mathrm{SiCH}_{2} \mathrm{CH}_{2} \mathrm{Si}, \mathrm{SiCH}\left(\mathrm{CH}_{3}\right) \mathrm{Si}\right)$, $0.14,0.08,0.06,0.04\left(\mathrm{~s}, \mathrm{SiMe}_{2}, \mathrm{SiMe}_{3}\right) ; \mathrm{C}, \mathrm{Si}$;

${ }^{13} \mathrm{C} \mathrm{NMR}\left(101 \mathrm{MHz}, \mathrm{CDCl}_{3}\right): \delta(\mathrm{ppm})=50.64,50.61(\mathrm{OMe}), 33.70,33.63,29.59,23.27,23.14,22.87$, 17.86, 14.25 (octyl chain), 8.43 (Si-CH$\left.{ }_{2} \mathrm{CH}_{2}-\mathrm{Si}\right), 7.60,5.07,\left(\mathrm{SiCH}\left(\mathrm{CH}_{3}\right) \mathrm{Si}\right), 2.01,1.62,0.64,0.19,-1.12$ $\left(\mathrm{SiCH}\left(\mathrm{CH}_{3}\right) \mathrm{Si}, \mathrm{SiMe}, \mathrm{SiMe}_{3}\right)$;

${ }^{29} \mathrm{Si} \mathrm{NMR}\left(79,5 \mathrm{MHz}, \mathrm{CDCl}_{3}\right): \delta(\mathrm{ppm})=-21.36,-22.35(-22.98)\left(\mathrm{SiMe}, \mathrm{SiMe}_{3}\right),-38.10,-41.51$ $\left(\mathrm{OSi}(\mathrm{OMe})_{3}\right)$. 
The selectivity of the reaction, determined by NMR spectroscopy, shows that the product contains a mixture of trimethoxysilylethyl $\alpha$ and $\beta$ groups in 34:66 ratio.

The purity and chemical structure of the compound were confirmed by NMR spectroscopy, and the following signals were assigned:

${ }^{1} \mathrm{H} \mathrm{NMR}\left(400 \mathrm{MHz}, \mathrm{CDCl}_{3}\right): \delta(\mathrm{ppm})=3.56(\mathrm{~s}, \mathrm{OMe}), 1.30-1.27\left(\mathrm{~m}\right.$, octyl $\left.-\mathrm{CH}_{2}-\right), 1.09(\mathrm{~d}, J=7.5 \mathrm{~Hz}$, trimethylsiloxy alpha product), $0.88\left(\mathrm{t}, \mathrm{J}=6.2 \mathrm{~Hz}\right.$, octyl $\left.-\mathrm{CH}_{3}\right), 0.61-0.50\left(\mathrm{~m}, \mathrm{SiCH}_{2} \mathrm{CH}_{2} \mathrm{Si}, \mathrm{SiCH}\left(\mathrm{CH}_{3}\right) \mathrm{Si}\right)$, 0.14, 0.08, 0.07, $0.04\left(\mathrm{~s}, \mathrm{SiMe}_{2}, \mathrm{SiMe}_{3}\right)$;

${ }^{13} \mathrm{C}$ NMR $\left(101 \mathrm{MHz}, \mathrm{CDCl}_{3}\right): \delta(\mathrm{ppm})=50.65(\mathrm{OMe}), 33.31,31.83,23.18,23.06,22.80,17.84,14.25$ (octyl chain), $8.42\left(\mathrm{Si}-\mathrm{CH}_{2} \mathrm{CH}_{2}-\mathrm{Si}\right), 1.98,1.58,0.64,-0.22,-1.14\left(\mathrm{Si}-\mathrm{CH}_{2} \mathrm{CH}_{2}-\mathrm{Si}, \mathrm{SiMe}_{2}, \mathrm{SiMe}_{3}\right)$;

${ }^{29} \mathrm{Si} \mathrm{NMR}\left(79,5 \mathrm{MHz}, \mathrm{CDCl}_{3}\right): \delta(\mathrm{ppm})=-21.22,-22.37(-22.82)\left(\mathrm{SiMe}, \mathrm{SiMe}_{3}\right),-38.00,-41.54$ $\left(\mathrm{OSi}(\mathrm{OMe})_{3}\right)$.

\subsection{Scanning Electron Miscroscopy}

SEM observations were performed to compare the effectiveness of laser patterning parameters with the actual state of the processed samples. Hence, reference specimens with no chemical modifiers were observed; then, the thickness of the lines and spacing distance were measured (included in Table 2). The images obtained are shown in Figure 6. In the upper right corner of each photo, an image of the droplet used for the wettability measurement for reference (details in Section 3.3.) is included.

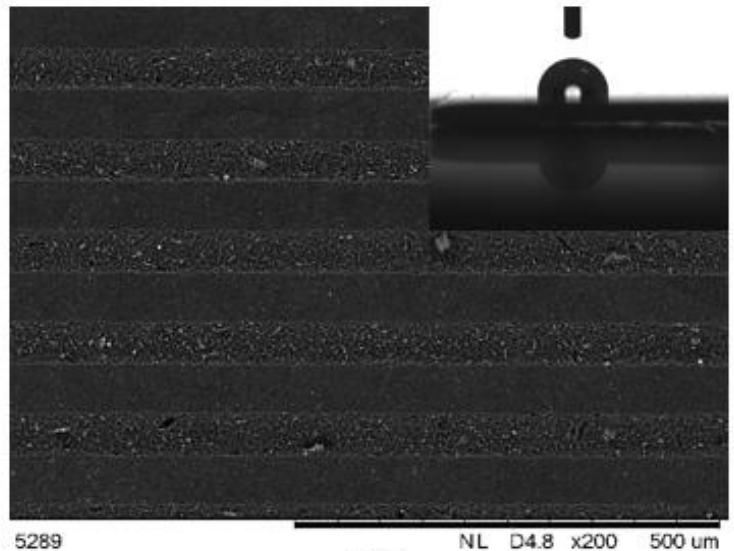

(a)

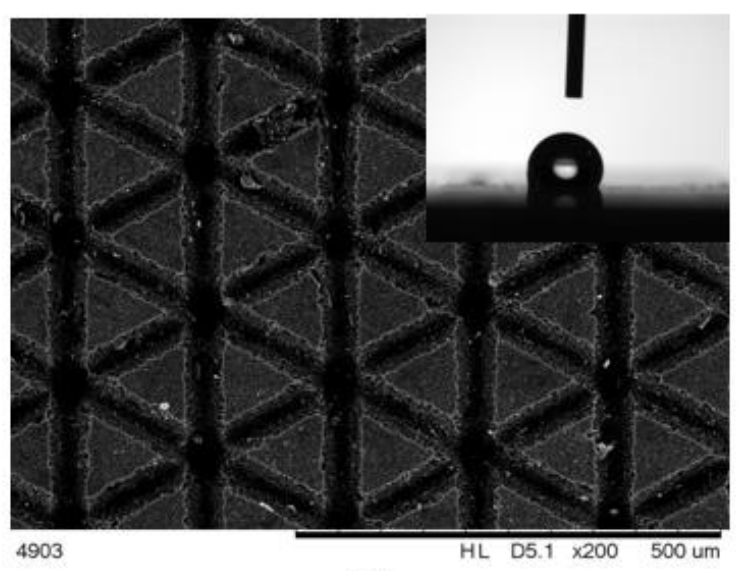

(c)

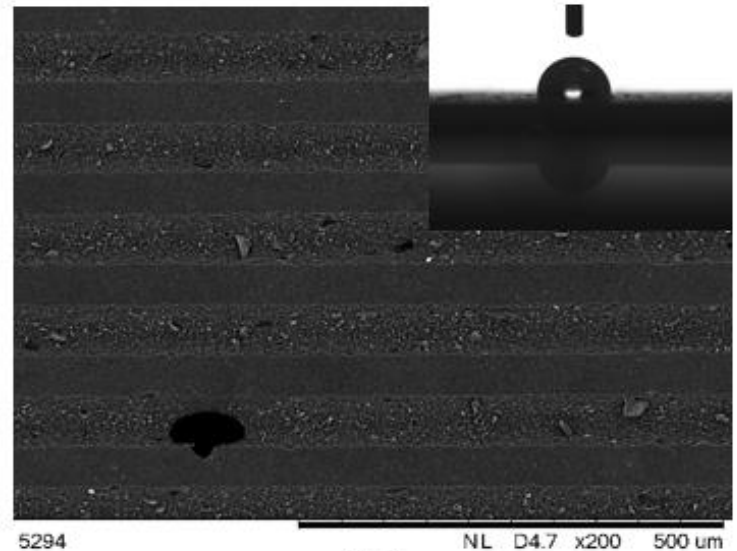

(b)

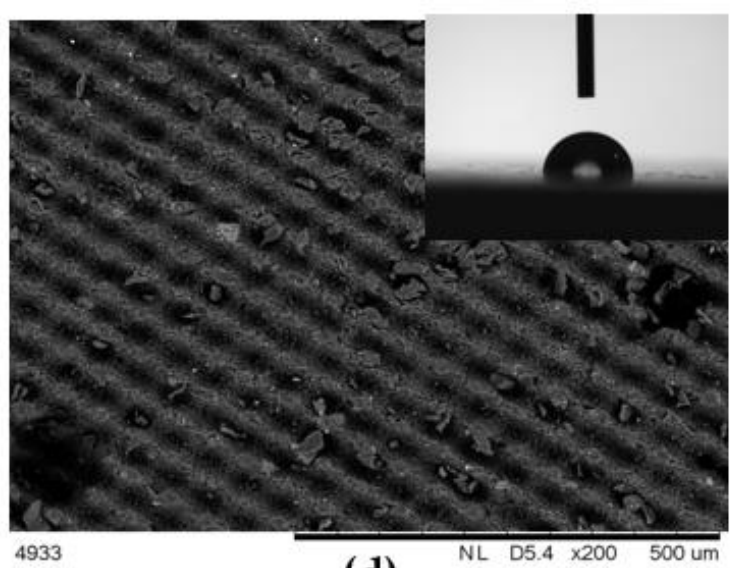

(d)

Figure 6. SEM images of reference samples with no chemical modification after laser processing. Laser processing type no. (a) 1 ; (b) 2 ; (c) 3 ; (d) 4 . 
Table 2. Parameters measured from SEM (scanning electron microscopy) images for reference samples.

\begin{tabular}{ccccc}
\hline $\begin{array}{c}\text { Processing } \\
\text { Type No. }\end{array}$ & Lens $(\mathbf{m m})$ & Pattern & Line Thickness $(\mu \mathrm{m})$ & $\begin{array}{c}\text { Measured Spacing } \\
\text { Distance }(\mu \mathrm{m})\end{array}$ \\
\hline 1 & 34 & Lines & $53.0 \pm 2.7$ & $115 \pm 6$ \\
2 & 34 & Lines & $63.0 \pm 3.2$ & $115 \pm 6$ \\
3 & 100 & Triangles & $46.0 \pm 2.3$ & $163 \pm 8$ \\
4 & 100 & Triangles & $39.6 \pm 2.0$ & $107 \pm 5$ \\
\hline
\end{tabular}

It can be seen both from the images and values taken from Table 2 that for sample processing types 1 and 2, where $34 \mathrm{~mm}$ lens was used, the obtained patterns are similar. While sample processing types 3 and 4 include the manufacturing of different patterns compared to processing no. 1 and 2 and the distinction is also very clear on the images. Comparing the spacing distance values from Tables 1 and 2, it can be seen that for processing types no. 1 and 2, distances measured on SEM images are equal, i.e., $115 \pm 6 \mu \mathrm{m}$, although higher than $100 \mu \mathrm{m}$ (Table 1) is set in laser parameters, which does not fall within the uncertainty range that was expected. Furthermore, $163 \pm 8 \mu \mathrm{m}$ spacing distance was obtained for processing type no. 3 , which is much higher than that of processing type no. 1 and 2 , but slightly smaller than the expected value of $180 \mu \mathrm{m}$. For processing type no. 4, the measured spacing distance is the smallest, $107 \pm 5 \mu \mathrm{m}$, even though the laser parameter set was $120 \mu \mathrm{m}$, i.e., bigger than for processing type no. 1 and 2.

Based on the images shown in Figure 6, it can be stated that the laser ablation was successful, as the coating was ablated in a controlled way. Patterns can be distinguished and the measured spacings are close to the applicated laser parameters.

\subsection{Surface's Profile}

In Table 3, the measured values of surface roughness parameters of the tested samples are shown. The given values represent the average values from 150 measurements.

Table 3. Roughness parameter values for samples before and after laser processing.

\begin{tabular}{cccccc}
\hline Chemical Modifier & Processing Type No. & Pattern & Lens $(\mathbf{m m})$ & $\boldsymbol{R}_{\boldsymbol{a}}(\boldsymbol{\mu m})$ & $\boldsymbol{R}_{\boldsymbol{z}}(\boldsymbol{\mu m})$ \\
\hline \multirow{3}{*}{ None } & None & None & None & $0.39 \pm 0.14$ & $1.9 \pm 0.1$ \\
& 1 & Lines & 34 & $3.80 \pm 0.18$ & $13.8 \pm 0.8$ \\
& 2 & Lines & 34 & $4.97 \pm 0.21$ & $17.7 \pm 0.8$ \\
& 3 & Triangles & 100 & $2.70 \pm 0.42$ & $13.3 \pm 1.7$ \\
& 4 & Triangles & 100 & $2.60 \pm 0.09$ & $11.6 \pm 0.7$ \\
\hline SILOX1 & None & None & None & $1.02 \pm 0.08$ & $7.1 \pm 0.5$ \\
5 wt. $\%$ & 1 & Lines & 34 & $6.67 \pm 0.41$ & $24.4 \pm 1.5$ \\
& 2 & Lines & 34 & $7.80 \pm 0.58$ & $29.5 \pm 2.0$ \\
& 3 & Triangles & 100 & $3.90 \pm 0.32$ & $18.3 \pm 1.5$ \\
& 4 & Triangles & 100 & $2.46 \pm 0.17$ & $11.8 \pm 0.8$ \\
\hline SILOX2 & None & None & None & $1.07 \pm 0.09$ & $7.1 \pm 0.3$ \\
5 wt. $\%$ & 1 & Lines & 34 & $6.30 \pm 0.69$ & $24.9 \pm 2.1$ \\
& 2 & Lines & 34 & $8.00 \pm 0.58$ & $31.0 \pm 2.1$ \\
& 3 & Triangles & 100 & $3.85 \pm 0.61$ & $17.8 \pm 2.5$ \\
& 4 & Triangles & 100 & $2.89 \pm 0.31$ & $14.4 \pm 1.3$ \\
\hline SILOX3 & None & None & None & $1.04 \pm 0.06$ & $7.2 \pm 0.2$ \\
5 wt. $\%$ & 1 & Lines & 34 & $7.80 \pm 0.36$ & $29.3 \pm 1.5$ \\
& 2 & Lines & 34 & $8.90 \pm 0.57$ & $34.4 \pm 1.6$ \\
& 3 & Triangles & 100 & $3.63 \pm 0.72$ & $16.9 \pm 2.9$ \\
& 4 & Triangles & 100 & $2.94 \pm 0.20$ & $14.0 \pm 0.8$ \\
\hline
\end{tabular}


Analyzing Table 3, it is visible that, in agreement with expectation, laser processing of the samples visibly increased roughness parameters, i.e., the values of $R_{a}$ of unprocessed reference samples are in the range of 0.39 and $1.04 \mu \mathrm{m}$, whereas the lowest value for a processed sample is $2.46 \pm 0.17 \mu \mathrm{m}$ and the highest is $8.90 \pm 0.57 \mu \mathrm{m}$.

Out of the laser processed specimens, the ones with no chemical modifiers have the lowest values of the roughness parameters; for processing type no. $4, R_{a}$ is as low as $2.60 \pm 0.09 \mu \mathrm{m}$, whereas $R_{z}$ is only $11.6 \pm 0.7 \mu \mathrm{m}$. Similar values were obtained for processing type no. 4 of the sample with SILOX1 modifier; nevertheless, the other processing types of the material with SILOX1 modifier produced rougher surfaces. Moreover, high values achieved for samples modified with SILOX3 should be noticed, e.g., for processing type no. $2, R_{a}$ is equal to $8.90 \mu \mathrm{m}$ and $R_{z}$ is $34.4 \mu \mathrm{m}$. Overall, chemical modifiers for all tested samples visibly increased the values of roughness parameters.

Furthermore, the characteristics may also be compared regarding the processing type.

Unprocessed samples clearly have the lowest values of both $R_{a}$ and $R_{z}$; even their standard deviation ranges do not overlap with any other ones. It is worth noting that the samples after processing type no. 2 exhibit the highest values of $R_{a}$ and $R_{z}$. Surfaces after processing type no. 1 are also relatively rough while processing type no. 4 obtains the flattest surfaces. There is a clear distinction between the high roughness of line pattern (processing type no. 1 and 2) and lower roughness of triangle pattern (processing types no. 3 and 4). When no chemical modification was implemented, samples after laser processing indicated lower values in comparison to samples with chemical additives treated using the same method.

The roughness parameters analysis (Table 3) was confronted with 3-dimensional profiles of the surfaces of the samples (Figure 7). The chosen profiles for samples with SILOX2 $5 \mathrm{wt}$ \% chemical modifier, and after laser processing, are representative for each laser processing type.

Based on the images and profiles acquired from the profilometer shown in Figure 7, it can be stated that the profiles are consistent with the images from SEM. The patterns are regular, with periodic distances between peaks and similar width of the peaks. Moreover, the surfaces after processing no. 1 and 2 are modified so that the deviations upwards from the reference plane are similar with those downwards, i.e., the pattern seems to be well controlled. Furthermore, the peaks of the surfaces visible in Figure 7a,b and $d$ are more regular, whereas for Figure $7 c$ each bigger peak consists of two smaller peaks. As the pattern in this processing was triangles, the lines in one direction probably formed deeper lines than the other one. For processing type no. 4 (Figure 7d), the crosscut profile shows some minor imperfections in the overall shape. However, there are no significant interruptions in the other profiles, nor deviations from the pattern. There are also some outlines of such shapes on Figure $7 \mathrm{~d}$; however, they are not as distinct and are probably due to the lower laser power set. 


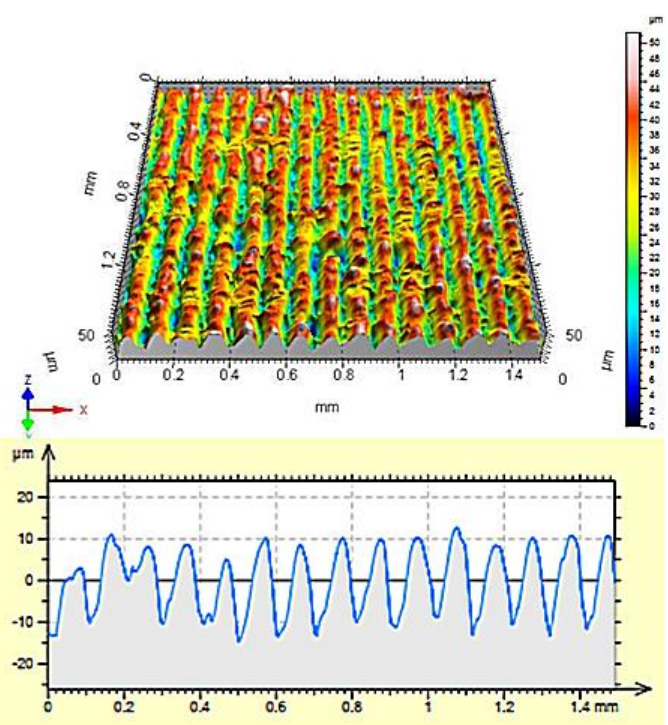

(a)
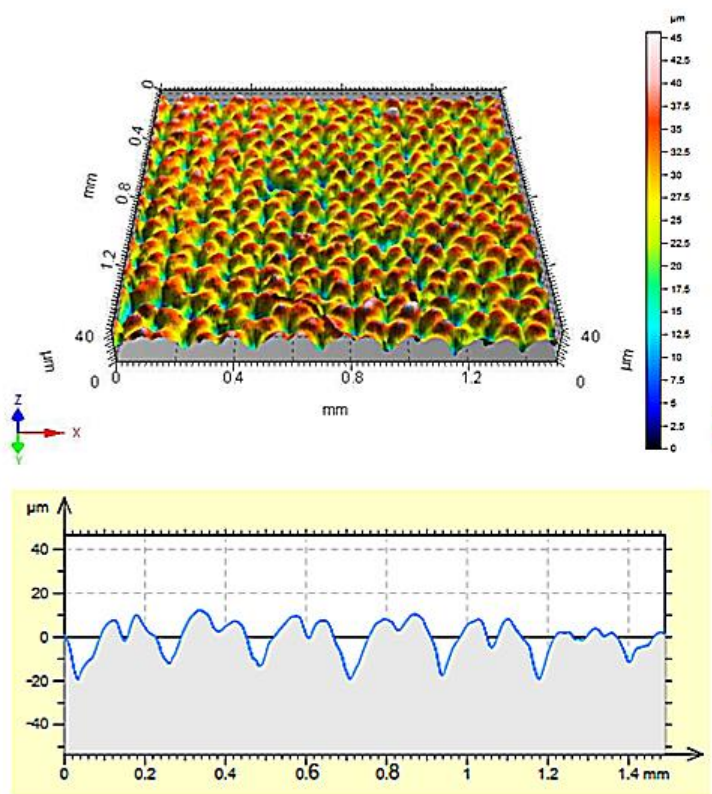

(c)

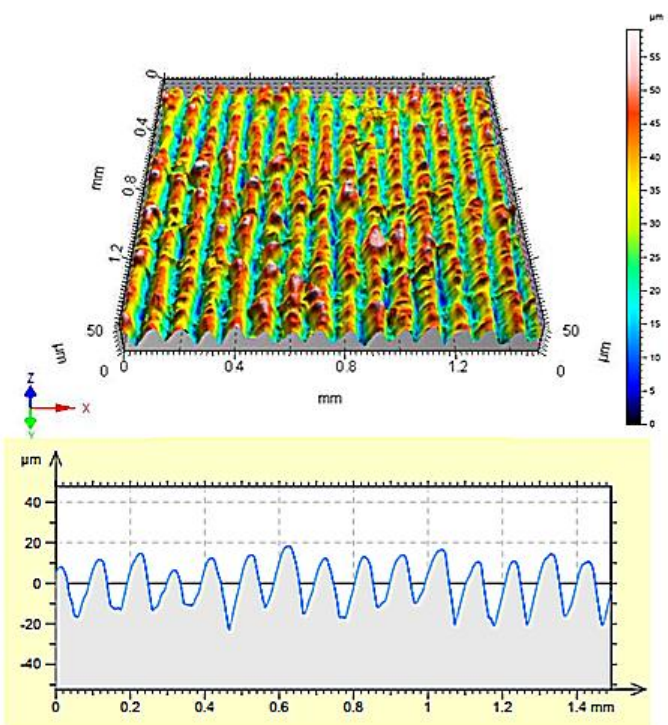

(b)
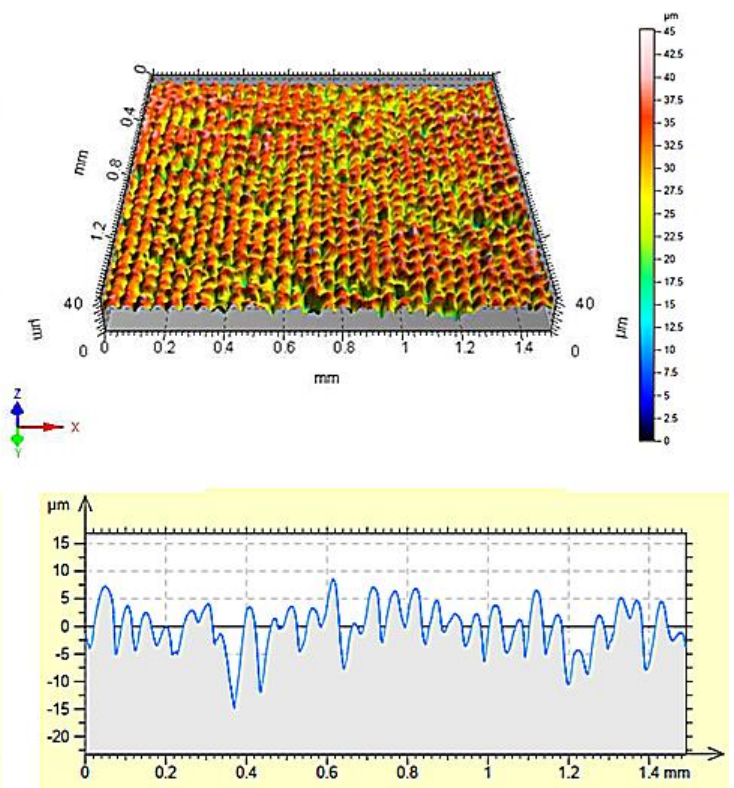

(d)

Figure 7. Representative surface profiles of the samples containing SILOX $25 \mathrm{wt} . \%$ after processing type no.: (a) 1 ; (b) 2; (c) 3; (d) 4 .

\subsection{Wettability}

Wettability of the materials was assessed based on the values of contact angle and contact angle hysteresis, which are shown in Table 4. The photos of the droplets on the surface of unprocessed samples are shown in Figure 6.

The reference coating (without chemical modifier and before laser processing) achieves a contact angle equal to $90 \pm 3^{\circ}$ and hence may be already considered hydrophobic. Nevertheless, it is exactly on the boundary between hydrophilicity and hydrophobicity, especially when taking into account the uncertainty. It may be seen that the use of chemical modifiers and laser patterning improves the hydrophobicity of the surfaces. For all samples with chemical modifiers, the best results have been achieved for processing type no. 2, where contact angles in the range 130-135 $5^{\circ}$ were measured. Interestingly, the reference samples after processing type no. 3 turned out to be the most beneficial; 
however, even then the contact angle was only $116 \pm 3^{\circ}$. From the set of unprocessed samples, the one with SILOX3 modifier is the most hydrophobic one as the contact angle is equal to $104 \pm 3^{\circ}$.

Table 4. Wettability characteristics of the samples.

\begin{tabular}{|c|c|c|c|c|c|c|c|}
\hline $\begin{array}{l}\text { Chemical } \\
\text { Modifier }\end{array}$ & $\begin{array}{c}\text { Processing } \\
\text { Type No. }\end{array}$ & Pattern & $\begin{array}{l}\text { Lens } \\
(\mathrm{mm})\end{array}$ & $\begin{array}{c}\text { Contact } \\
\text { Angle }\left({ }^{\circ}\right)\end{array}$ & $\begin{array}{c}\text { Advancing } \\
\text { Contact } \\
\text { Angle }\left(^{\circ}\right)\end{array}$ & $\begin{array}{c}\text { Receding } \\
\text { Contact } \\
\text { Angle }\left(^{\circ}\right)\end{array}$ & $\begin{array}{c}\text { Contact } \\
\text { Angle } \\
\text { Hysteresis }\left({ }^{\circ}\right)\end{array}$ \\
\hline \multirow{5}{*}{ None } & None & None & None & $90 \pm 3$ & $102 \pm 5$ & $68 \pm 4$ & $34 \pm 2$ \\
\hline & 1 & Lines & 34 & $100 \pm 3$ & $113 \pm 6$ & $81 \pm 4$ & $32 \pm 1$ \\
\hline & 2 & Lines & 34 & $103 \pm 3$ & $116 \pm 6$ & $83 \pm 5$ & $33 \pm 2$ \\
\hline & 3 & Triangles & 100 & $116 \pm 3$ & $120 \pm 6$ & $89 \pm 5$ & $31 \pm 1$ \\
\hline & 4 & Triangles & 100 & $90 \pm 2$ & $95 \pm 5$ & $62 \pm 3$ & $33 \pm 2$ \\
\hline \multirow{5}{*}{$\begin{array}{c}\text { SILOX1 } \\
5 \text { wt. } \%\end{array}$} & None & None & None & $101 \pm 3$ & $111 \pm 6$ & $90 \pm 5$ & $21 \pm 1$ \\
\hline & 1 & Lines & 34 & $129 \pm 4$ & $137 \pm 7$ & $123 \pm 6$ & $14 \pm 1$ \\
\hline & 2 & Lines & 34 & $135 \pm 4$ & $143 \pm 4$ & $117 \pm 6$ & $26 \pm 1$ \\
\hline & 3 & Triangles & 100 & $112 \pm 3$ & $119 \pm 6$ & $90 \pm 5$ & $29 \pm 1$ \\
\hline & 4 & Triangles & 100 & $123 \pm 4$ & $131 \pm 4$ & $104 \pm 6$ & $27 \pm 1$ \\
\hline \multirow{5}{*}{$\begin{array}{l}\text { SILOX2 } \\
5 \text { wt. } \%\end{array}$} & None & None & None & $96 \pm 3$ & $108 \pm 6$ & $87 \pm 5$ & $21 \pm 1$ \\
\hline & 1 & Lines & 34 & $113 \pm 3$ & $118 \pm 6$ & $88 \pm 5$ & $30 \pm 1$ \\
\hline & 2 & Lines & 34 & $130 \pm 4$ & $141 \pm 6$ & $117 \pm 6$ & $24 \pm 1$ \\
\hline & 3 & Triangles & 100 & $101 \pm 3$ & $109 \pm 6$ & $69 \pm 4$ & $40 \pm 2$ \\
\hline & 4 & Triangles & 100 & $103 \pm 3$ & $112 \pm 6$ & $84 \pm 5$ & $28 \pm 1$ \\
\hline \multirow{5}{*}{$\begin{array}{c}\text { SILOX3 } \\
5 \text { wt. } \%\end{array}$} & None & None & None & $104 \pm 3$ & $110 \pm 6$ & $88 \pm 5$ & $22 \pm 1$ \\
\hline & 1 & Lines & 34 & $126 \pm 4$ & $133 \pm 6$ & $116 \pm 6$ & $17 \pm 1$ \\
\hline & 2 & Lines & 34 & $132 \pm 4$ & $142 \pm 5$ & $134 \pm 6$ & $8 \pm 1$ \\
\hline & 3 & Triangles & 100 & $113 \pm 3$ & $119 \pm 6$ & $90 \pm 5$ & $29 \pm 1$ \\
\hline & 4 & Triangles & 100 & $118 \pm 4$ & $125 \pm 6$ & $98 \pm 5$ & $27 \pm 1$ \\
\hline
\end{tabular}

Contact angle hysteresis is the smallest for sample processing type no. 2 for the sample with SILOX3 chemical modifier, as the angle in this case is equal to $8 \pm 1^{\circ}$. Overall, specimens with modifiers SILOX1 and SILOX3 achieved smaller values of hysteresis in comparison to samples containing SILOX2. Samples with SILOX2 after processing type no. 3 achieved the highest value of CAH c.a. $40 \pm 2^{\circ}$. Therefore, it can be seen that the highest values of contact angle hysteresis were obtained after processing type no. 3. In regard to no laser patterning, specimens with chemical modifiers have lower contact angle hysteresis than the sample where the chemical composition was unchanged.

\subsection{Ice Adhesion}

In Table 5, there are collected values of ice adhesion of the tested samples.

The meaning behind "break" in Table 5 is that all samples that were tested after any type of laser processing broke before the sample was released from the frozen holder. Therefore, it is deduced that the ice adhesion was higher than the tensile strength of the samples (min. $600 \mathrm{kPa}$ ). Nevertheless, it can be seen that the unprocessed samples with chemical modifiers did not break and actually varied the value of ice adhesion achieved, which for the reference sample is $346 \mathrm{kPa}$. Modifiers SILOX1 and SILOX3 significantly decreased ice adhesion to the surface compared to the reference sample, as the values achieved were around $253 \mathrm{kPa}$, and $271 \mathrm{kPa}$, respectively. On the contrary, SILOX2 increased the value to $417 \mathrm{kPa}$; thus, further increase in ice adhesion is expected for laser-treated samples. Hence, it can be concluded that SILOX1 and SILOX3 modifiers increase the anti-icing behavior of the material. 
Table 5. Ice adhesion test results.

\begin{tabular}{|c|c|c|c|c|}
\hline Chemical Modifier & Processing Type No. & Pattern & Lens (mm) & Ice Adhesion (kPa) \\
\hline \multirow{5}{*}{ None } & None & None & None & $346 \pm 17$ \\
\hline & 1 & Lines & 34 & Break \\
\hline & 2 & Lines & 34 & Break \\
\hline & 3 & Triangles & 100 & Break \\
\hline & 4 & Triangles & 100 & Break \\
\hline \multirow{5}{*}{ SILOX1 } & None & None & None & $253 \pm 13$ \\
\hline & 1 & Lines & 34 & Break \\
\hline & 2 & Lines & 34 & Break \\
\hline & 3 & Triangles & 100 & Break \\
\hline & 4 & Triangles & 100 & Break \\
\hline \multirow{5}{*}{ SILOX2 } & None & None & None & $417 \pm 21$ \\
\hline & 1 & Lines & 34 & Break \\
\hline & 2 & Lines & 34 & Break \\
\hline & 3 & Triangles & 100 & Break \\
\hline & 4 & Triangles & 100 & Break \\
\hline \multirow{5}{*}{ SILOX3 } & None & None & None & $271 \pm 14$ \\
\hline & 1 & Lines & 34 & Break \\
\hline & 2 & Lines & 34 & Break \\
\hline & 3 & Triangles & 100 & Break \\
\hline & 4 & Triangles & 100 & Break \\
\hline
\end{tabular}

\subsection{Freezing Time Delay}

Due to the best ice adhesion results of samples modified with SILOX1, freezing delay time tests were carried out on specimens with this chemical modifier, i.e., the ones with no laser processing and processing type no. 3 and 4 . The results for the samples and the reference specimen are included in Table 6.

Table 6. Results of freezing delay time test compared with roughness, contact angle and ice adhesion.

\begin{tabular}{cccccccc}
\hline $\begin{array}{c}\text { Chemical } \\
\text { Modifier }\end{array}$ & $\begin{array}{c}\text { Processing } \\
\text { Type No. }\end{array}$ & Pattern & $\begin{array}{c}\text { Freezing } \\
\text { Delay Time }\end{array}$ & CA $\left(^{\circ}\right)$ & $\boldsymbol{R}_{\boldsymbol{a}}(\boldsymbol{\mu m})$ & $\boldsymbol{R}_{\boldsymbol{z}}(\boldsymbol{\mu m})$ & $\begin{array}{c}\text { IA } \\
(\mathbf{k P a})\end{array}$ \\
\hline None & None & None & $3 \mathrm{~min} 20 \mathrm{~s}$ & $90 \pm 3$ & $0.39 \pm 0.14$ & $1.9 \pm 0.1$ & $347 \pm 17$ \\
\hline $\begin{array}{c}\text { SILOX1 } \\
5 \text { wt. } \%\end{array}$ & None & None & $18 \mathrm{~min} 54 \mathrm{~s}$ & $101 \pm 3$ & $1.02 \pm 0.08$ & $7.1 \pm 0.5$ & $253 \pm 13$ \\
\hline $\begin{array}{c}\text { SILOX1 } \\
5 \text { wt. } \%\end{array}$ & 1 & Lines & $\begin{array}{c}23 \mathrm{~min} \\
42 \mathrm{~s}\end{array}$ & $129 \pm 4$ & $6.67 \pm 0.41$ & $24.4 \pm 1.5$ & Break \\
\hline $\begin{array}{c}\text { SILOX1 } \\
5 \text { wt. } \%\end{array}$ & 2 & Lines & $\begin{array}{c}21 \mathrm{~min} \\
32 \mathrm{~s}\end{array}$ & $135 \pm 4$ & $7.80 \pm 0.58$ & $29.5 \pm 2.0$ & Break \\
\hline $\begin{array}{l}\text { SILOX1 } \\
5 \text { wt. } \%\end{array}$ & 3 & Triangles & $>1 \mathrm{~h} 20 \mathrm{~min}$ & $112 \pm 3$ & $3.90 \pm 0.32$ & $18.3 \pm 1.5$ & Break \\
\hline $\begin{array}{l}\text { SILOX1 } \\
5 \text { wt. } \%\end{array}$ & 4 & Triangles & $18 \mathrm{~min} 37 \mathrm{~s}$ & $123 \pm 4$ & $2.46 \pm 0.17$ & $11.8 \pm 0.8$ & Break \\
\hline
\end{tabular}

Clearly, chemical modification of the coating increased the freezing time, as the reference sample's freezing delay time was only $3 \min 20 \mathrm{~s}$. Values obtained for the unprocessed samples with SILOX1 and 
the one after processing type no. 4 are similar to each other, both not much under 19 min. Furthermore, FDT of samples with SILOX1 and line pattern no. 1 and 2 are also close, both a little over 20 min. The freezing delay time of chemically modified samples after processing type no. 3 is significantly extended as it exceeds $1 \mathrm{~h} 20 \mathrm{~min}$. It can be concluded that chemical modification and laser processing increases the value of freezing delay time. Hence, it can be seen that even though laser processing did not lower the ice adhesion, it improved anti-icing behavior in the aspect of freezing delay time, especially for laser processing no. 3. In Table 6, there are also collected values of roughness parameters for correlation analysis It can be seen that the longest FDT was observed for the surface with rather mediocre roughness and contact angle. Furthermore, the addition of chemical modifiers not only extended the freezing time of a droplet, but also decreased its ice adhesion to the surface.

\section{Discussion}

In this section of the paper, there are comparisons of different parameters obtained in the research, separated with respect to the chemical modifiers used. The diagrams are based on Tables 4-6.

In Figure 8, the values of contact angles and roughness parameters of samples with no chemical modifiers are shown, i.e., reference samples. There is no unambiguous connection between contact angle values and roughness parameters. The highest contact angle was achieved for the sample after laser processing type no. 3 , but both $R_{a}$ and $R_{z}$ exhibit only average values. The other way around, the lowest contact angle was obtained for no laser processing and laser processing type no. 4, where the roughness parameters for the unprocessed reference samples are really low and for the processed samples are higher, but actually lower than for processing type no. 1-3.

In Figure 9, the contact angle, ice adhesion, $R_{a}, R_{z}$, and freezing delay time values of samples containing SILOX1 $5 \mathrm{wt}$ \% modifier are shown. First of all, it can be seen that the ice adhesion values are lower for the chemically modified samples. The lack of values for laser processed samples was described in Section 3.4 but means, overall, that ice adhesion values are higher than the tensile strength of the material. Moreover, freezing delay time increases for chemically modified samples. Hence, it can be stated that the increased roughness improves the icephobic behavior of the material with SILOX1 $5 \mathrm{wt}$ \% $\%$ in respect to not forming ice easily, although the relation is not straightforward, as the roughest surface is not the most icephobic one. Furthermore, in this case, contact angles' growth is seemingly (with the exception of processing type 3) related to an increase in roughness parameter values, meaning that the hydrophobic properties improve as well. On the other hand, for samples after processing type 3, it can be seen that the distance between laser lines (Table 1) is much higher $(180 \mu \mathrm{m})$ in comparison to the rest of samples $(100$ and $120 \mu \mathrm{m})$. This can significantly influence higher freezing delay time by forming larger air pockets between the surface and droplet and thus limiting heat transfer independently of wettability. This is driven not only by roughness, but also by chemical additives.

In Figure 10, the contact angle, ice adhesion, $R_{a}$ and $R_{z}$ values of samples with SILOX2 5 wt.\% chemical modifier are shown. For these samples, ice adhesion actually increases after adding the chemical modifiers. There is some correlation between contact angle values and roughness parameters, as for the roughest surface, the contact angle is the highest and for the least rough surface, the contact angle is the lowest. The values in between are also consistent with the theory when taking into account the ranges of standard deviation values. In this case, it also seems that the hydrophobic behavior of the material increases with its surface's roughness.

Contact angle, ice adhesion, $R_{a}$ and $R_{z}$ values of specimens modified with SILOX3 5 wt. \% are shown in Figure 11. The analysis is analogical to that of Figure 10, i.e., the samples with the addition of SILOX1 experience a decrease in the value of ice adhesion. Furthermore, the hydrophobicity improves with increasing roughness as well. 


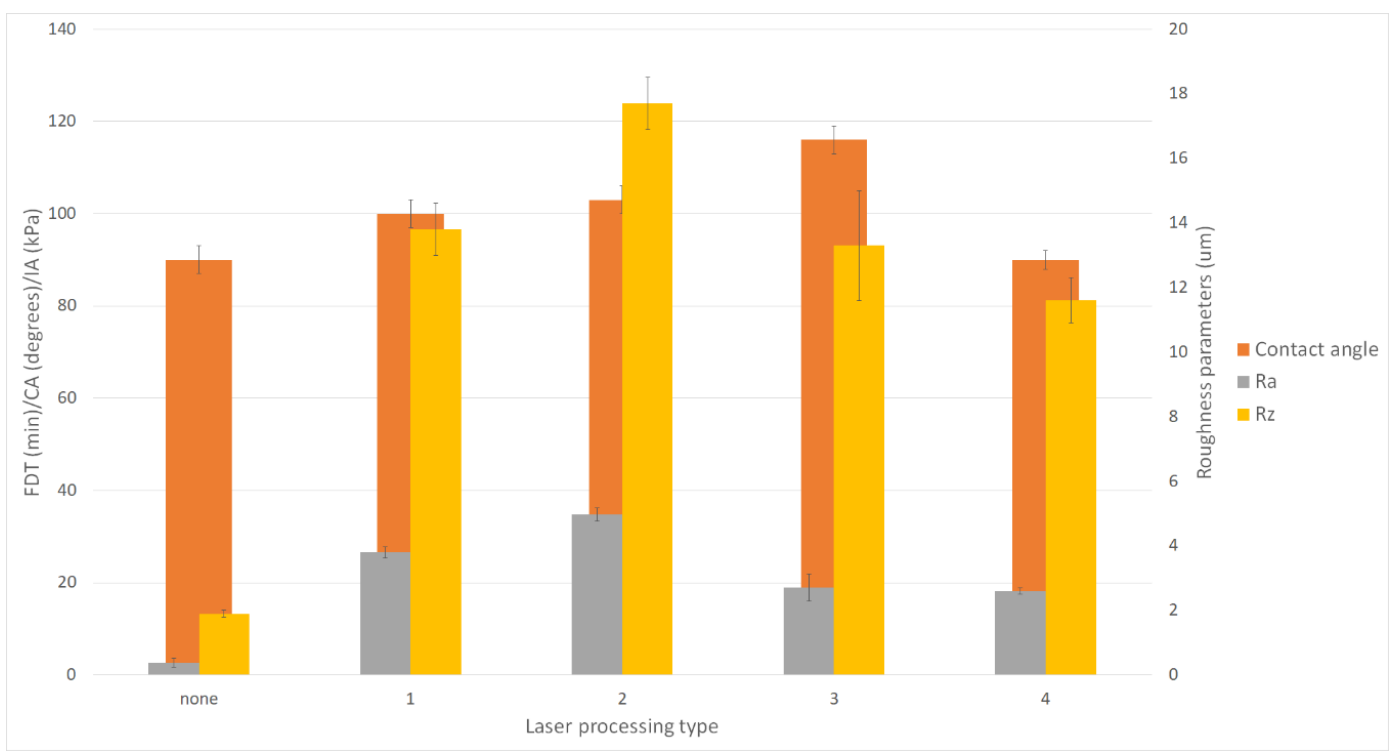

Figure 8. Characteristics of samples with no chemical modifier for different laser processing types.

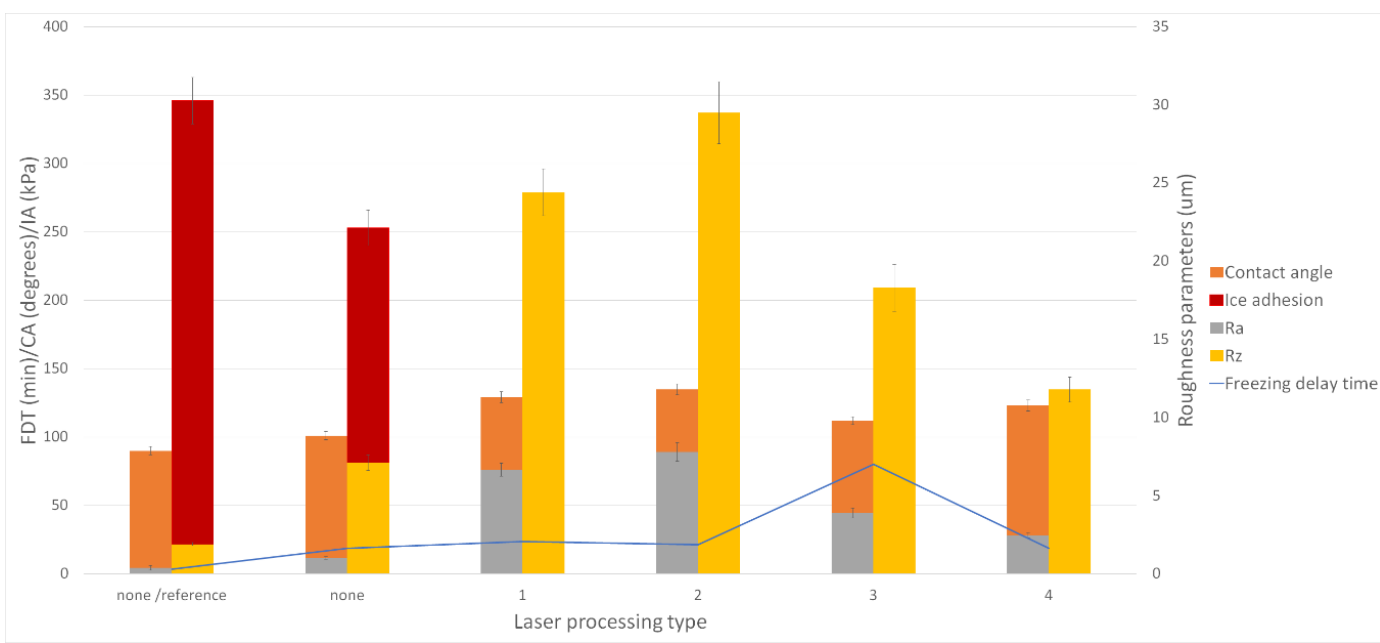

Figure 9. Characteristics of samples with SILOX1 5 wt.\% chemical modifier.

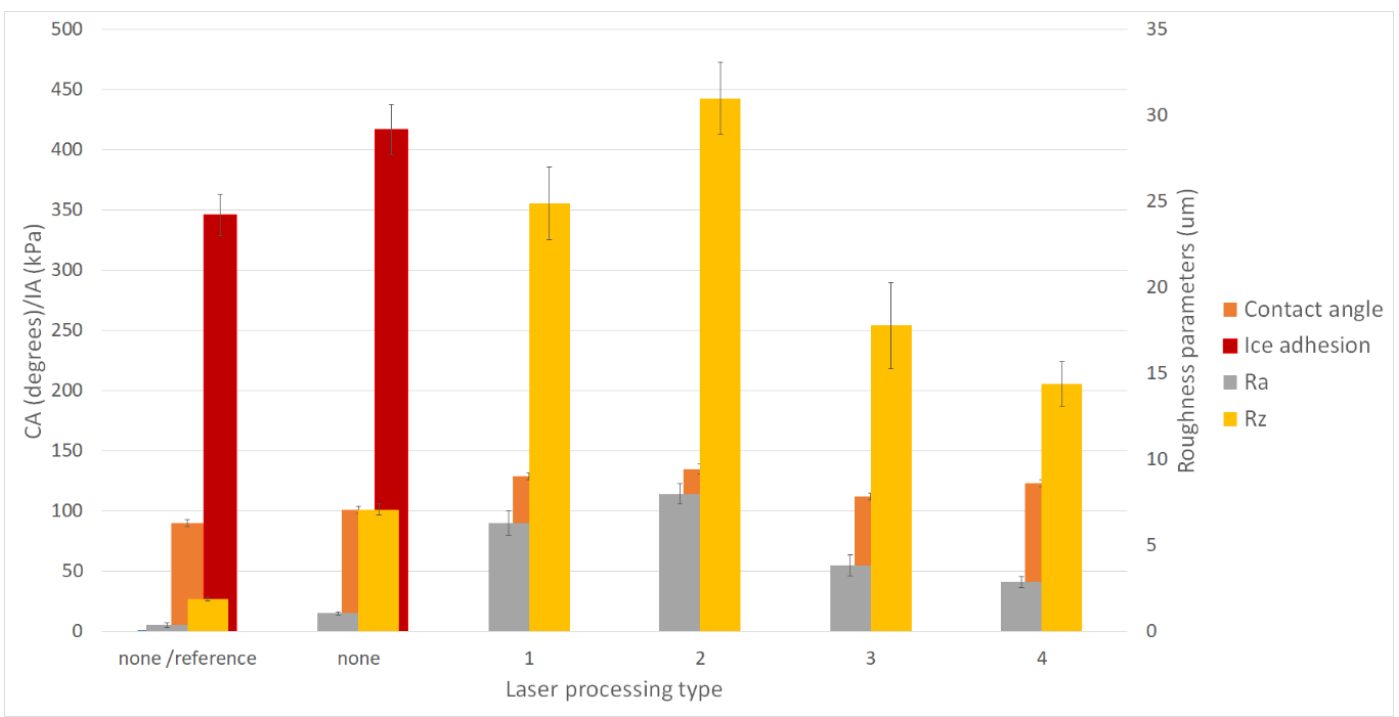

Figure 10. Characteristics of samples with SILOX2 5 wt.\% chemical modifier. 


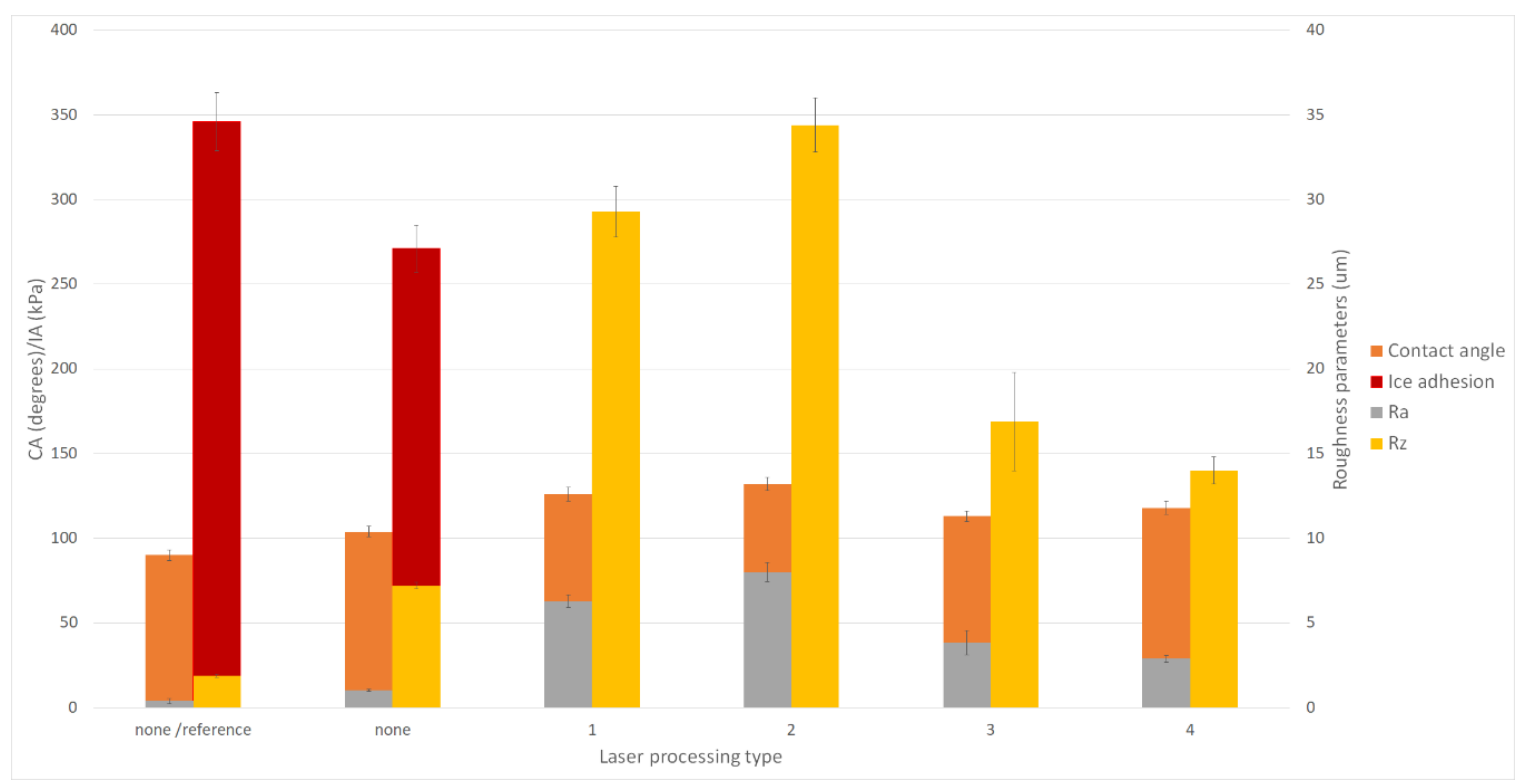

Figure 11. Characteristics of samples with SILOX3 5 wt.\% chemical modifier.

\section{Conclusions}

Three new results included in this paper confirm that chemical modifiers and laser patterning increase the hydrophobicity of polyester-based coatings. Moreover, the impact of laser parameters set in the processing is crucial. It can be stated that out of the proposed surface modifications, processing type no. 2, i.e., line and $3 \mathrm{~W}$ laser power, yields the best results. The goal of decreasing ice adhesion strength to the surface by means of chemical modification has been achieved. The usage of SILOX1, SILOX2, and SILOX3 $5 \mathrm{wt}$ \% chemical modifiers also visibly improves the material's hydrophobicity. The most hydrophobic materials were achieved by combining processing type no. 2 and chemical modifiers. Overall, rougher surfaces show better hydrophobic properties. Ice adhesion tests proved that even though laser patterning increased the hydrophobicity of the materials up to $140^{\circ}$, very rough surfaces did not exhibit improved anti-icing properties, showing values higher than the strength of the samples. However, in the same test, it was found that the chemical modifiers SILOX1 and SILOX3 improve the icephobic characteristics. Anti-icing behavior exhibited by the material due to the use of the chemical modifier SILOX1 was also confirmed by means of an increased freezing delay time. It should be admitted that there is no clear correlation between ice adhesion strength and wettability contact angle. Characteristics of the tested systems are complex as there are numerous variables such as chemical structure and chemical modifiers, its content in the material, surface geometry, and roughness. Further research is planned to analyze the correlations in more depth.

Author Contributions: Conceptualization, R.K., B.S.; methodology, B.P.; validation, R.P. writing original draft Z.D.K.; investigation, R.B., M.T., X.G.-C., A.B. (Ana Borras); supervision, A.B. (Anna Boczkowska). All authors have read and agreed to the published version of the manuscript.

Funding: This research was funded by National Centre for Research and Development (NCBiR), grant number LIDER/16/0068/L-9/17/NCBR/2018.

Acknowledgments: Authors acknowledge the funding from the EU H2020 research and innovation program under agreement number 899352 (project SOUNDofICE).

Conflicts of Interest: The authors declare no conflict of interest.

\section{References}

1. Komusanac, I.; Brindley, G.; Fraile, D. Wind energy in Europe in 2019. Trends and Statistics. Available online: https://windeurope.org/about-wind/statistics/european/wind-energy-in-europe-in-2019/f (accessed on 16 September 2020). 
2. Wind Explained. Electricity Generation from Wind. Available online: https://www.eia.gov/energyexplained/ wind/electricity-generation-from-wind.php\#: \{\}:text=U.S.totalannualElectricitygeneration,U.S.utilityscaleelectricitygeneration (accessed on 16 September 2020).

3. Simani, S. Overview of Modelling and Advanced Control Strategies for Wind Turbine Systems. Energies 2015, 8, 13395-13418. [CrossRef]

4. Tavner, P.J.; Greenwood, D.M.; Whittle, M.W.G.; Gindele, R.; Faulstich, S.; Hahn, B. Study of weather and location effects on wind turbine failure rates. Wind Energy 2013, 175-187. [CrossRef]

5. Ibrahim, M.E.; Medraj, M. Water droplet erosion ofwind turbine blades: Mechanics, testing, modeling and future perspectives. Materials 2020, 13, 157. [CrossRef]

6. Zhang, S.; Dam-Johansen, K.; Bernad, P.L.; Kiil, S. Rain erosion of wind turbine blade coatings using discrete water jets: Effects of water cushioning, substrate geometry, impact distance, and coating properties. Wear 2015, 328-329, 140-148. [CrossRef]

7. Das, S.; Kumar, S.; Samal, S.K.; Mohanty, S.; Nayak, S.K. A Review on Superhydrophobic Polymer Nanocoatings: Recent Development and Applications. Ind. Eng. Chem. Res. 2018, 57, 2727-2745. [CrossRef]

8. Jiang, Z.; Wang, X.; Jia, H.; Zhou, Y.; Ma, J.; Liu, X.; Jiang, L.; Chen, S. Superhydrophobic polytetrafluoroethylene/ heat-shrinkable polyvinyl chloride composite film with super anti-icing property. Polymers 2019, 11, 805. [CrossRef] [PubMed]

9. Yilgor, I.; Bilgin, S.; Isik, M.; Yilgor, E. Facile preparation of superhydrophobic polymer surfaces. Polymer 2012, 53, 1180-1188. [CrossRef]

10. Cohen, N.; Dotan, A.; Dodiuk, H.; Kenig, S. Superhydrophobic Coatings and Their Durability. Mater. Manuf. Process. 2016, 31, 1143-1155. [CrossRef]

11. Battisti, L. Optimising wind turbine design for operation in cold climates. Wind Energy Syst. Optimising Des. Constr. Safe Reliab. Oper. 2010, 388-460. [CrossRef]

12. Dalili, N.; Edrisy, A.; Carriveau, R. A review of surface engineering issues critical to wind turbine performance. Renew. Sustain. Energy Rev. 2009, 13, 428-438. [CrossRef]

13. Tiwari, A. A Study of Icephobic Coatings. Part I. PCI Magazine. 2020, pp. 38-42. Available online: https: //www.pcimag.com/articles/106963-a-study-of-icephobic-coatings-part-1 (accessed on 15 January 2020).

14. Karthikeyan, N.; Anand, R.B.; Suthakar, T.; Barhate, S. Materials, Innovations and Future Research Opportunities on Wind Turbine Blades-Insight Review. Environ. Prog. Sustain. Energy 2019, 38. [CrossRef]

15. Liu, J.; Wang, J.; Mazzola, L.; Memon, H.; Barman, T.; Turnbull, B.; Mingione, G.; Choi, K.S.; Hou, X. Development and evaluation of poly(dimethylsiloxane) based composite coatings for icephobic applications. Surf. Coat. Technol. 2018, 349, 980-985. [CrossRef]

16. Nishimura, R.; Hyodo, K.; Sawaguchi, H.; Yamamoto, Y.; Nonomura, Y.; Mayama, H.; Yokojima, S.; Nakamura, S.; Uchida, K. Fractal Surfaces of Molecular Crystals Mimicking Lotus Leaf with Phototunable Double Roughness Structures. J. Am. Chem. Soc. 2016, 138, 10299-10303. [CrossRef] [PubMed]

17. Jamil, M.I.; Ali, A.; Haq, F.; Zhang, Q.; Zhan, X.; Chen, F. Icephobic Strategies and Materials with Superwettability: Design Principles and Mechanism. Langmuir 2018, 34, 15425-15444. [CrossRef] [PubMed]

18. Schutzius, T.M.; Jung, S.; Maitra, T.; Eberle, P.; Antonini, C.; Stamatopoulos, C.; Poulikakos, D. Physics of icing and rational design of surfaces with extraordinary icephobicity. Langmuir 2015, 31, 4807-4821. [CrossRef] [PubMed]

19. Wu, X.; Silberschmidt, V.V.; Hu, Z.T.; Chen, Z. When superhydrophobic coatings are icephobic: Role of surface topology. Surf. Coat. Technol. 2019, 358, 207-214. [CrossRef]

20. Mishchenko, L.; Hatton, B.; Bahadur, V.; Taylor, J.A.; Krupenkin, T.; Aizenberg, J. Design of ice-free nanostructured surfaces based on repulsion of impacting water droplets. ACS Nano 2010, 4, 7699-7707. [CrossRef]

21. Sojoudi, H.; Wang, M.; Boscher, N.D.; McKinley, G.H.; Gleason, K.K. Durable and scalable icephobic surfaces: Similarities and distinctions from superhydrophobic surfaces. Soft Matter 2016, 12, 1938-1963. [CrossRef]

22. Sataeva, N.E.; Boinovich, L.B.; Emelyanenko, K.A.; Domantovsky, A.G.; Emelyanenko, A.M. Laser-assisted processing of aluminum alloy for the fabrication of superhydrophobic coatings withstanding multiple degradation factors. Surf. Coat. Technol. 2020, 397, 125993. [CrossRef]

23. Vercillo, V.; Tonnicchia, S.; Romano, J.M.; García-Girón, A.; Aguilar-Morales, A.I.; Alamri, S.; Dimov, S.S.; Kunze, T.; Lasagni, A.F.; Bonaccurso, E. Design Rules for Laser-Treated Icephobic Metallic Surfaces for Aeronautic Applications. Adv. Funct. Mater. 2020, 30. [CrossRef] 
24. Ossi, P.M. Springer Series in Materials Science. In Advances in the Application of Lasers in Materials Science; Springer: Cham, Switzerland, 2018; Volume 274, ISBN 9783319968445.

25. Hauschwitz, P.; Jagdheesh, R.; Alamri, S.; Rostohar, D.; Kunze, T.; Brajer, J.; Kopeček, J.; Mocek, T. Fabrication of functional superhydrophobic surfaces on carbon fibre reinforced plastics by IR and UV direct laser interference patterning. Appl. Surf. Sci. 2020, 508. [CrossRef]

26. Volpe, A.; Gaudiuso, C.; Di Venere, L.; Licciulli, F.; Giordano, F.; Ancona, A. Direct femtosecond laser fabrication of superhydrophobic aluminum alloy surfaces with anti-icing properties. Coatings 2020, 10, 587. [CrossRef]

27. Lang, V.; Voisiat, B.; Lasagni, A.F. High throughput direct laser interference patterning of aluminum for fabrication of super hydrophobic surfaces. Materials 2019, 12, 1484. [CrossRef] [PubMed]

28. Yang, H.; Xu, K.; Xu, C.; Fan, D.; Cao, Y.; Xue, W.; Pang, J. Femtosecond Laser Fabricated Elastomeric Superhydrophobic Surface with Stretching-Enhanced Water Repellency. Nanoscale Res. Lett. 2019, 14. [CrossRef]

29. Peter, A.; Lutey, A.H.A.; Faas, S.; Romoli, L.; Onuseit, V.; Graf, T. Direct laser interference patterning of stainless steel by ultrashort pulses for antibacterial surfaces. Opt. Laser Technol. 2020, 123, 105954. [CrossRef]

30. Milles, S.; Soldera, M.; Voisiat, B.; Lasagni, A.F. Fabrication of superhydrophobic and ice-repellent surfaces on pure aluminium using single and multiscaled periodic textures. Sci. Rep. 2019, 9, 13944. [CrossRef]

31. Zheng, H.; Chang, S.; Ma, G.; Wang, S. Anti-icing performance of superhydrophobic surface fabricated by femtosecond laser composited dual-layers coating. Energy Build. 2020, 223, 110175. [CrossRef]

32. Lasagni, A.F.; Roch, T.; Langheinrich, D.; Bieda, M.; Wetzig, A. Large area direct fabrication of periodic arrays using interference patterning. Phys. Procedia 2011, 12, 214-220. [CrossRef]

33. Florian, C.; Skoulas, E.; Puerto, D.; Mimidis, A.; Stratakis, E.; Solis, J.; Siegel, J. Controlling the Wettability of Steel Surfaces Processed with Femtosecond Laser Pulses. ACS Appl. Mater. Interfaces 2018, 10, 36564-36571. [CrossRef]

34. Varlamova, O.; Hoefner, K.; Ratzke, M.; Reif, J.; Sarker, D. Modification of surface properties of solids by femtosecond LIPSS writing: Comparative studies on silicon and stainless steel. Appl. Phys. A Mater. Sci. Process. 2017, 123, 725. [CrossRef]

35. Du, Q.; Ai, J.; Qin, Z.; Liu, J.; Zeng, X. Fabrication of superhydrophobic/superhydrophilic patterns on polyimide surface by ultraviolet laser direct texturing. J. Mater. Process. Technol. 2018, 251, 188-196. [CrossRef]

36. Alamri, S.; Lasagni, A.F. Development of a general model for direct laser interference patterning of polymers. Opt. Express 2017, 25, 9603. [CrossRef] [PubMed]

37. Vercillo, V.; Cardoso, J.T.; Huerta-Murillo, D.; Tonnicchia, S.; Laroche, A.; Mayén Guillén, J.A.; Ocaña, J.L.; Lasagni, A.F.; Bonaccurso, E. Durability of superhydrophobic laser-treated metal surfaces under icing conditions. Mater. Lett. X 2019, 3, 100021. [CrossRef]

38. Liu, B.; Zhang, K.; Tao, C.; Zhao, Y.; Li, X.; Zhu, K.; Yuan, X. Strategies for anti-icing: Low surface energy or liquid-infused? RSC Adv. 2016, 6, 70251-70260. [CrossRef]

39. Susoff, M.; Siegmann, K.; Pfaffenroth, C.; Hirayama, M. Evaluation of icephobic coatings-Screening of different coatings and influence of roughness. Appl. Surf. Sci. 2013, 282, 870-879. [CrossRef]

40. Guo, J.; Yang, F.; Guo, Z. Fabrication of stable and durable superhydrophobic surface on copper substrates for oil-water separation and ice-over delay. J. Colloid Interface Sci. 2016, 466, 36-43. [CrossRef]

41. Li, H.; Zhao, W.; Fang, Z. Hydrophobic Pd nanocatalysts for one-pot and high-yield production of liquid furanic biofuels at low temperatures. Appl. Catal. B Environ. 2017, 215, 18-27. [CrossRef]

42. Lawrence, N.J.; Drew, M.D.; Bushell, S.M. Polymethylhydrosiloxane: A versatile reducing agent for organic synthesis. J. Chem. Soc. Perkin Trans. 1999, 1, 3381-3391. [CrossRef]

43. Marciniec, B. Hydrosilylation: A Comprehensive Review on Recent Advances; Springer Science Business Media: Berlin/Heidelberg, Germany, 2009.

44. Jindasuwan, S.; Suwan, M.; Supothina, S. Bifunctional water-repellent and flame-retardant cotton fabric coated with poly(Methylhydrogen siloxane) and ammonium phosphate. Chiang Mai J. Sci. 2018, 45, 2211-2219.

45. Elzaabalawy, A.; Meguid, S.A. Development of novel superhydrophobic coatings using siloxane-modified epoxy nanocomposites. Chem. Eng. J. 2020, 398, 125403. [CrossRef]

46. Przybylak, M.; Maciejewski, H.; Dutkiewicz, A.; Wesołek, D.; Władyka-Przybylak, M. Multifunctional, strongly hydrophobic and flame-retarded cotton fabrics modified with flame retardant agents and silicon compounds. Polym. Degrad. Stab. 2016, 128, 55-64. [CrossRef] 
47. Gadelmawla, E.S.; Koura, M.M.; Maksoud, T.M.A.; Elewa, I.M.; Soliman, H.H. Roughness parameters. J. Mater. Process. Technol. 2002, 123, 133-145. [CrossRef]

48. Extrand, C.W.; Kumagai, Y. Advancing and Receding Contant Angle of PTFE. J. Colloid Interface Sci. 1997, 191, 378-383. [CrossRef] [PubMed]

49. Law, K.Y. Definitions for hydrophilicity, hydrophobicity, and superhydrophobicity: Getting the basics right. J. Phys. Chem. Lett. 2014, 5, 686-688. [CrossRef]

50. Zhu, C.X.; Zhu, C.L.; Zhao, W.W.; Tao, M.J. Experimental Study on the Shear Adhesion Strength between the Ice and Substrate in Icing Wind Tunnel. J. Mech. 2018, 34, 209-216. [CrossRef]

Publisher's Note: MDPI stays neutral with regard to jurisdictional claims in published maps and institutional affiliations.

(C) 2020 by the authors. Licensee MDPI, Basel, Switzerland. This article is an open access article distributed under the terms and conditions of the Creative Commons Attribution (CC BY) license (http://creativecommons.org/licenses/by/4.0/). 